\title{
Beyond designed functional margins in CANDU type NPP. Radioactive nuclei assessment in an LOCA type accident
}

\author{
Andrei Razvan Budu and Gabriel Lazaro Pavel* \\ University Politehnica of Bucharest, Faculty of Power Engineering, Splaiul Independentei No. 313, Sector 6, Bucharest, 060042, \\ Romania
}

Received: 5 May 2015 / Received in final form: 20 September 2015 / Accepted: 6 October 2015 Published online: 09 December 2015

\begin{abstract}
European Union's energy roadmap up to year 2050 states that in order to have an efficient and sustainable economy, with minimum or decreasing greenhouse gas emissions, along with use of renewable resources, each constituent state has the option for nuclear energy production as one desirable option. Every scenario considered for tackling climate change issues, along with security of supply positions the nuclear energy as a recommended option, an option that is highly competitive with respect to others. Nuclear energy, along with other renewable power sources are considered to be the main pillars in the energy sector for greenhouse gas emission mitigation at European level. European Union considers that nuclear energy must be treated as a highly recommended option since it can contribute to security of energy supply. Romania showed excellent track-records in operating in a safe and economically sound manner of Cernavoda NPP Units $1 \& 2$. Both Units are in top 10 worldwide in terms of capacity factor. Due to Romania's need to ensure the security of electricity supply, to meet the environmental targets and to move to low carbon generation technologies, Cernavoda Units $3 \& 4$ Project appears as a must. This Project was started in 2010 and it is expected to have the Units running by 2025. Cost effective and safety operation of a Nuclear Power Plant is made taking into consideration functional limits of its equipment. As common practice, every nuclear reactor type (technology used) is tested according to the worse credible accident or equipment failure that can occur. For CANDU type reactor, this is a Loss of Cooling Accident (LOCA). In a LOCA type accident in a CANDU NPP, using RELAP/SCDAP code for fuel bundle damage assessment the radioactive nuclei are to be quantified. Recently, CANDU type NPP accidents are studied using the RELAP/SCDAP code only. The code formerly developed for PWR type reactors was adapted for the CANDU geometry and can assess the accident progression consequences up to a certain point. The code assesses the fuel bundle damage progression, but cannot assess further core damage for a CANDU type core, and starting from these data the amount of damaged fuel can be calculated. The radio nuclei present in the damaged fuel are supposed to be released into the main heat transport system and after that into the containment building in the worst case scenario. Assessing the radioactive nuclei maximum release is the purpose of the present paper. The radioactive nuclei release is needed for the accident management plan, limiting the environmental and population impact of the supposed accident, and furthermore for a later site remediation plan that can be put in action after the complete mitigation of the accident consequences. The maximum quantity of radio nuclei released during the accident calculated in this paper is a worst case scenario evaluation that can lead to better preparedness in an accident scenario.
\end{abstract}

\section{Introduction}

Nuclear power is today among the non- $\mathrm{CO}_{2}$ emitting energy sources and nuclear fuel reserves are surpassing the fossil fuel reserves in terms of potential energy production.

Although there are many reactor years of experience in the design and operation field of nuclear power plants,

\footnotetext{
*e-mail: gabriel.pavel@gmail.com
}

events through the years have shown that there is no certainty to safe nuclear power operation and nuclear risk arises from even the most mundane operation activities.

Thus, even though best estimate evaluations of nuclear safety are performed for every type of operating nuclear power plant, the worst case scenario can lead to innovating new solutions for future nuclear power plants.

This paper proposes new values for release factors for fission products resulting from a severe accident, starting from the fuel bundle damage occurring in a LOCA/LOECC 
(Loss of Cooling Accident/Loss of Emergency Core Cooling) accident in a CANada Deuterium Uranium (CANDU) type Nuclear Power Plant (NPP).

The paper presents beforehand the main steps in using the SCDAP/RELAP5 code for CANDU type NPP severe analysis, and modifying the code to suit that type of power plants characteristics, and a severe accident transient to evaluate the fuel bundle and fuel pins damage occurred.

The fuel damage occurred leads to the release factor calculated and proposed for use in future environmental impact assessment done for a CANDU type NPP.

\section{SCDAP/RELAP5 use in CANDU type NPP accident analysis}

RELAP5 is a Light Water Reactor (LWR) transient analysis code developed initially for the US NRC at the Idaho National Laboratory as a base for nuclear power plant analysis, operating manual review, licensing calculations auditing and nuclear power regulation. It has a mono-dimensional transitory hydrodynamic model, with two-phase flow of water-steam mixture that may contain non-condensable components in the steam phase and a soluble component in the liquid phase.

The SCDAP/RELAP5 coupled code was developed for best-estimate simulation of light water reactors during severe accidents. The code models behavior of the main reactors cooling system coupled with that of the core and radioactive fission product release during a severe accident. This is the result of the unification of the RELAP5 used for thermal-hydraulic analysis, the study of control systems interaction, reactor kinetics and non-condensable gases transport with the SCDAP code that models the core behavior during severe accidents. The result is a flexible tool due to its generic approach to modeling that allows the modeling of specific systems according with the demand and is used consequently in the study of a large transient collection for power stations, research reactors and experiments in small installations.

Due to the moderator and cooling agent separation and horizontal flow in the fuel channels in the CANDU core, direct use of the detailed core degradation models of the existing system codes as SCDAP/RELAP5, MELCOR, ICARE/CATHARE or ATHLET-CD cannot be done. But, due to the flexibility of SCDAP/RELAP5 code and validation results for other reactor system analysis, the early phase modeling of some severe CANDU6 type accident was done. Furthermore, based on studies linked to those simulations, basic evaluation of the code aptitudes was conducted along with its development and adaptation needs due to the special conditions and phenomena in severe accidents for CANDU systems.

The SCDAP/RELAP5 code is adaptable to CANDU power plants systems due to heavy water library use and horizontal flow modeling capabilities. From the beginning of SCDAP/RELAP5 use in Romania, the code was added to, modified and improved to meet CANDU specifications.

The first step in the early stages was the use of the SCDAP/RELAP5 code in modeling a severe accident in a CANDU type coolant loop. Figure 1 shows an early complete mapping used to analyze a LOCA type accident in

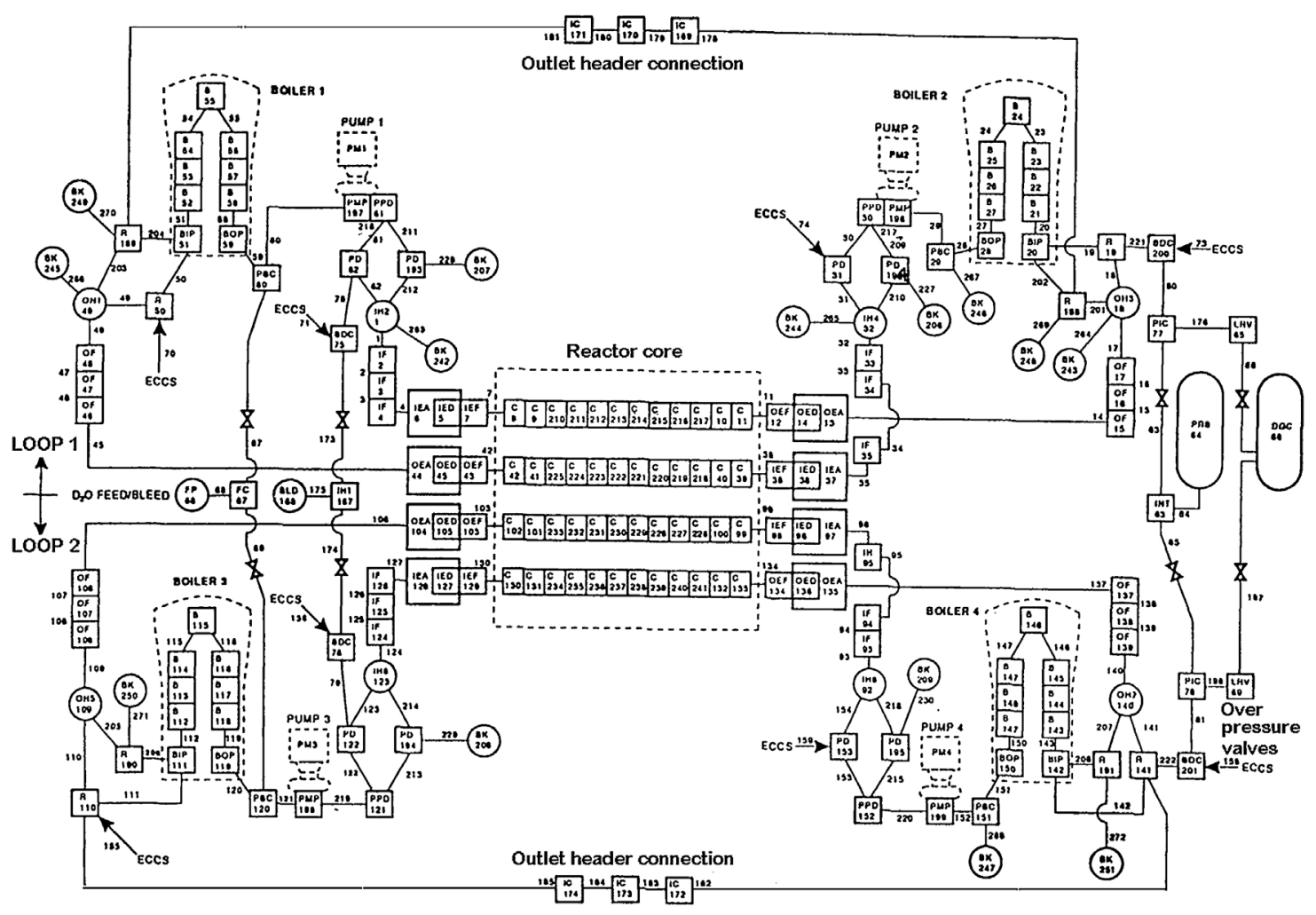

Fig. 1. CANDU coolant main circuit mapping [1]. 


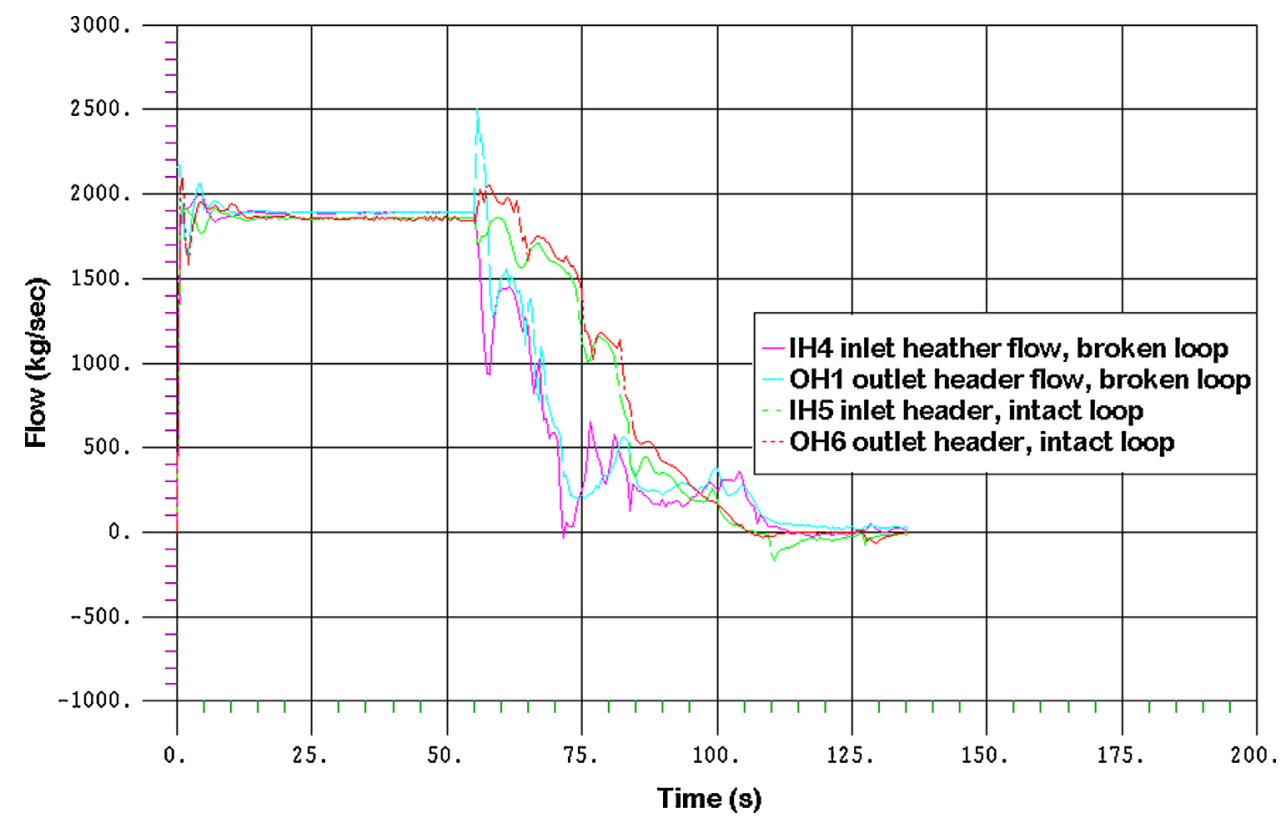

Fig. 2. Flow variation in LOCA accident with $100 \%$ break of inlet header [1].

a CANDU NPP using SCDAP/RELAP5. The accident presumes complete failure of a reactor coolant inlet header that deprives the reactor of the decay heat removal even after reactor emergency shutdown. Figure 2 shows flow through the system as the accident progresses. These results are the outcome of a $\mathrm{PhD}$ thesis defended in University Politehnica of Bucharest by Negut Gheorghe.

Another important step in the adaptation of the SCDAP/RELAP5 code for the CANDU NPP severe accident analysis was modifying it for analysis of the early phases of a loss of coolant accident with loss of the emergency core cooling system LOCA/LOECC.

In this accident the coolant loss leads to the fuel pins heat up and internal structure loss for the horizontal fuel bundle. The initial vertical typical PWR fuel bundle is losing its structural integrity in a completely different way than the CANDU bundle. Due to horizontal stacking of the fuel pins and the fuel bundle end plates, the pins sag and the bundles collapse to the bottom of the fuel channel. The collapse of the fuel bundle, added to the lack of coolant can lead to poor cooling for some pins and better for others due to steam flow rerouting, as shown in Figure 3 [2]. This configuration for the fuel bundle was used in the SCDAP/ RELAP5 modified model.

This configuration was calculated by a new restart file at the moment that a temperature reaches $1400 \mathrm{~K}$ in the fuel bundle and the cladding loses its mechanical resistance. Beyond this point, a bypass flow channel was introduced to account for the modified conditions surrounding the fuel pins. After the bundle collapses, the bypass channel occupies around $48 \%$ of the initial heat transfer surface of the channel; meanwhile, the total channel surface for the fuel pins was reduced to only $52 \%$ worsening the heat transfer to the coolant.

After this result came the need to modify the way that material relocates during the melting of the fuel pins. In the original PWR model, molten droplets move axially along the fuel pin due to the vertical position of the bundle. The horizontal position of the CANDU bundle means that molten droplets move along the pins circumference and pool at the bottom of the flow channel.

A new horizontal geometry model was created by the collaboration of a group from University Politehnica of Bucharest and the Nuclear Research Institute of Pitesti and contained modifications of the LIQSOL module included in the original SCDAP/RELAP5 code. A presumption for the new module is that there is material relocation between pins that implies a new possibility: pins that are not melting and have an intact oxide layer or have solidified drops on them can receive molten material from the melting pins surrounding them. A fraction of a molten droplet out of a fuel pin can come into contact with another pin or even the pressure tube. After that the droplets cannot change their axial position. They only can move along the pin circumference.

Figures 4 and 5 show the intact fuel bundle with different power rated pins and the collapsed bundle with the different coolant availability and cooling conditions.

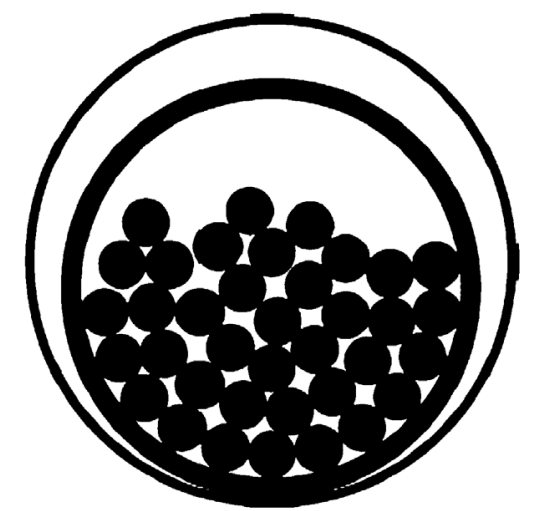

Fig. 3. Flow rerouting due to bundle collapse [3]. 


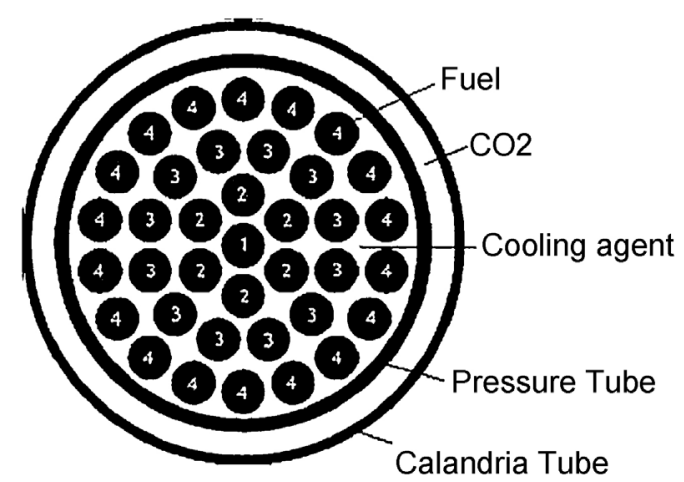

Fig. 4. Intact fuel bundle [4].

In Figure 4 [4] we can observe the four different types of pins used to model the CANDU fuel bundle. The intact bundle has four types of pins according to the different power rating of the pins. Thermal neutrons have the moderator as their source, thus the most outside ring of fuel pins receiving the highest neutron flux and producing more power than the inner ring pins. The pins in Figure 5 [4] are numbered according to the different cooling conditions. Due to coolant depravations, the pins at the bottom of the fuel channel receive less steam than the ones at the top of the collapsed bundle due to thermal stacking of the fluid left in the fuel channel.

Model used implies that the droplets are released at the point that the temperature reaches the point of initial oxide layer breakage. This means that the melted material is available to relocate at the set temperature independent from the oxidation status. This temperature may be even between 2098 and $2125 \mathrm{~K}$ (or the beta Zr melting margin). The temperature at which the droplets continue to relocate is set 50 degrees over the temperature at which the intact shield starts to flow in order to avoid mixing the droplets from the intact shield with the ones melted after solidifying, although the model permits the existence of both relocation pathways. The physical motive is the increase of melting temperature for the droplets compared to the intact shield due to hydrogen addition.

Modifying the LIQSOL module was the work of M. Mladin as part of his $\mathrm{PhD}$ thesis, the results of which were published, some of them being listed in the references section for this paper $[2,3]$.

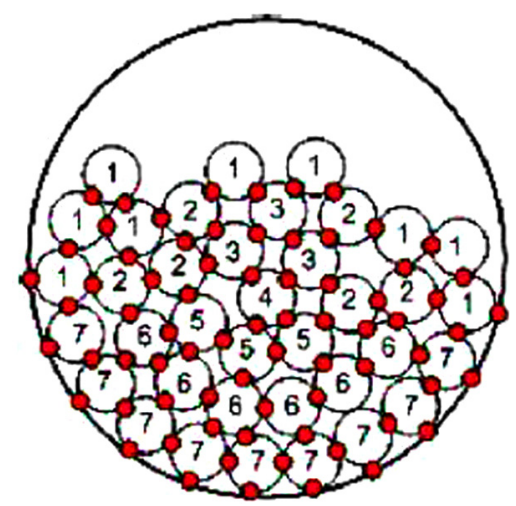

Fig. 5. Collapsed fuel bundle [4].
Although the SCDAP/RELAP5 code is suitable for CANDU type severe accident analysis, modifications to the code in order to better use it on this type of reactor were performed only in Romania by M. Mladin.

\section{Fuel degradation analysis in a LOCA/ LOECC accident}

This section analyses the parameter evolution on the maximum power channel for a CANDU 600 reactor during a LOCA type accident. The analysis implies the loss of moderator cooling (considered a heat sink during CANDU accident sequences) due to moderator pump failure. In addition, for the worst case scenario calculation, there is a loss of emergency core cooling system during the hole sequence [5].

The aim is to determine the extent of fuel degradation during the accident. The case study illustrated below presumes loss of coolant circulation through the pressure tube in a 100,000 seconds transient, the first 1000 seconds modeling a stationary, normal operation status. Coolant flow starts from $24 \mathrm{~kg} / \mathrm{s}$ in normal operation, decreasing to $5 \mathrm{~kg} / \mathrm{s}$ between the 1000 and the 1002 seconds and stabilized at $5 \mathrm{~g} / \mathrm{s}$ during the whole transient.

At the start of the accident, the reactor is shut down, decay and oxidation heat being the sources for the fuel bundle heat-up and melt. The 2000 seconds mark the loss of moderator cooling.

The radioactive nuclei possibly released out of the containment depend on the amount of fuel bundles/pins destroyed during a transient. The worst case scenario is the one in which all of the radioactive nuclei inventory is released and assessing the release is closely linked to the amount of fuel bundles or pins damaged during the transient.

In the conditions listed above, the fuel bundles defects were evaluated by the SCDAP/RELAP5 code between 0 (undamaged pin) up to 1 (totally damaged pin). In the model fuel pins have different power ratings, the ones in the outside ring in the bundle receiving the higher rating and the central pin the lowest, so damage occurs in the outside ring pins rather that in the central pin.

Figure 6 shows damage progression for the outside ring pins and as it is depicted six central fuel bundles suffer total damage during the transient, the other six being only slightly damaged.

The fuel pins on the internal fuel bundle rings were almost undamaged due to low power operation, so we can conclude that the release of radioactive nuclei is mainly due to the outside ring pins.

\section{Radioactive nuclei evaluation}

In June 2014, the Canadian Nuclear Safety Commission released a draft report, "Study of Consequences of a Hypothetical Severe Nuclear Accident and Effectiveness of Mitigation Measures". This study lists the fractions for equilibrium core inventory of radionuclide contained in the fuel released to the environment as can be observed below. 


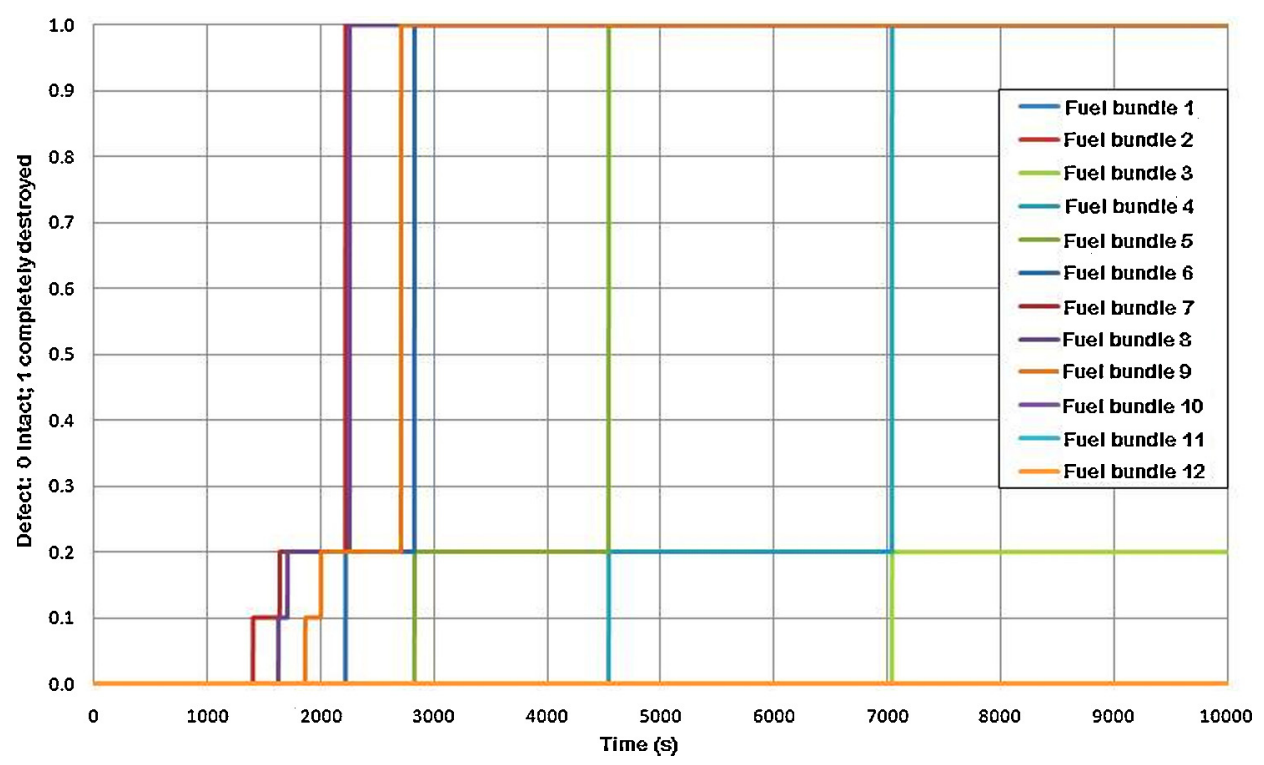

Fig. 6. Fuel degradation for the outside fuel pin ring in the CANDU bundle [5].

These release fractions can be used to assess the environmental impact of a severe accident and, furthermore, to develop the mitigation actions to be carried by the authorities after a postulated event. The amount of radioactive material released is thus important to the plans and costs for the mitigation measures.

In the previous section we have shown results that indicate the damage of the outer ring fuel pins for six fuel bundles in a CANDU channel during a LOCA/LOECC accident. The outer ring contains 18 fuel pins that are supposed to be totally damaged during the transient.

For a worst case scenario assumption, we are proposing to modify the source term used in environmental impact assessment in order to accommodate for a larger release as the one considered in Table 1.

The evaluation takes into account the number of bundles affected by the accident, the pin rings that are the most affected by the accident, and the total release of the inventory present in the damaged fuel pins, regardless of their position in the fuel channel or in the fuel bundle.

Table 1. Fission product groupings of the generic large release.

\begin{tabular}{ll}
\hline Fission product group & Release fraction \\
\hline Noble gases & 0.412 \\
Halogens & 0.00152 \\
Alkali metals & 0.00152 \\
Alkaline earths & $2.3 \times 10^{-8}$ \\
Refractory metals & 0.000253 \\
Lanthanides & $8.51 \times 10^{-9}$ \\
Actinides & $5.16 \times 10^{-8}$ \\
Barium & $1.68 \times 10^{-7}$ \\
\hline
\end{tabular}

Source term CNSC-Study [6].
Given the number of bundles affected by the accident and the number of pins from each bundle, we can estimate a different release fraction, unified for all the groupings.

$$
R f=A p / T n p,
$$

where $R f$ is the release fraction, $A p$ is the number of affected pins in the channel, Tnp is the total number of pins in the channel.

We can assume that the entire inventory of the damaged pins is released, in the worst case scenario due to transportation in the containment and unforeseen events that lead to containment failure (and the Fukushima event gives the means for this assumption).

Thus:

$$
T n p=P n \times N f b,
$$

where $P n$ is the total pins number per bundle (37 for CANDU 600), and Nfb the number of fuel bundles in a channel (12 for CANDU 600).

And:

$$
A p=\operatorname{Orp} \times D f n,
$$

where Orp is the outside ring pins number (18 in this case), and $D f n$ the damaged fuel bundle number (6 in this case).

We can calculate $A p=108$, and $T n p=444$, giving a release factor of 0.2432 , higher than the one used in the CNSC evaluation.

This higher value for the release factor leads to different mitigation actions in case of a nuclear severe accident, and proper measures can lead to lower environmental impact.

In the aftermath of the earthquake that shook Japan, and the following tsunami, the Fukushima Daiichi nuclear power plant released an important amount of radioactive material in the environment. This radioactive material must be, at present time, collected and accounted for in order to reduce the consequences of the accident and to 
restore the normal living conditions in the area affected by the accident.

The initial state restoration activities after a severe nuclear accident are directly linked to the released amount of radioactive material, and proper planning for these activities is of utmost importance.

After the Chernobyl disaster, the clean-up operations were carried out by the military and all the cost was engulfed in the communist economic system, all military or civilian personnel using state-provided equipment and all costs being neglected.

In our days, with the majority of nuclear power plant located in non-communist countries, the mitigation cost for a severe nuclear power plant accident must be provided for either by the utility owner or by the authority through special funds, and the necessary funds ready at any time.

These funds must be very well spent in order to optimize the cost/effects ratio. A well-evaluated released quantity of radioactive nuclei leads to a well thought plan of action, depending of course on weather conditions. A larger release needs a bigger effort and that effort may be well coordinated if the quantities are well evaluated from the start.

For example, a lower quantity released, along with the improper evaluation leads to over-evaluating the personnel and equipment needed to mitigate the consequences, and mobilizing a large number of unnecessary people and equipment is not cost effective.

Another example is the case in which the evaluation is below the released quantities, and the under-evaluation leads to poor mitigation results.

This means that a proper evaluation of the source term for the environmental release of radio nuclides is very important for the costs and people and material resources mobilized in the mitigation actions.

\section{Conclusions}

European Union (EU) through its legislation and directives set an action plan up to year 2050 (SET Plan ${ }^{1}$ ) which describes the pathway the energy sector has to follow in order to be at the forefront of EU citizen's needs. In order to reduce EU dependency on primary energy it is recommended to each member state to produce and follow a valid strategy with respect to energy. This strategy should be based on security of supply, on ensuring a comfortable energy mix and to reduce the losses. EU leaves the option to each member state to decide the best suitable energy mix for respective country. Along with renewable sources of energy, the nuclear industry is perceived as a major player in greenhouse gas reduction and in safe and secure provider for power with predictable and affordable prices.

Safe operation of all types of NPPs has been observed all over Europe. One key element on defining safety for a nuclear power plant is analyzing its functional margins, its safe limits for operation. R\&D has played a major role and brought a huge contribution to this situation.

\footnotetext{
${ }^{1}$ http://ec.europa.eu/energy/en/topics/technology-and-innovation/strategic-energy-technology-plan, as of 22.2.2015.
}

SCDAP/RELAP5 code can be used for severe accident analysis for the CANDU 6 type reactor due to heavy water properties library and horizontal flow calculations capabilities. Starting from these premises, the code was adapted and used for CANDU type NPP severe accident analysis and it can be used to assess the fuel bundle and fuel pin damage in a LOCA/LOECC accident with loss of moderator cooling.

The code was used to model different systems for the CANDU type reactor and power plant in other countries other than Romania but it has been modified to take into account the horizontal geometry of the fuel bundles during severe accident analysis.

The results of the analysis done using SCDAP/ RELAP5 are used to estimate the release factor for fission products present in the fuel as a worst case scenario evaluation. These factors are higher than the ones calculated and used in source term evaluation in a recently release study performed by the CNSC study.

This evaluation is meant as a starting point towards a better assessment of the radioactive contamination following a severe nuclear power plant accident.

Better assessment of release factors lead to better preparedness of the authorities and of the involved institutions, utility owner or government, better planning and thus in better use of funds and human resources in a severe nuclear power plant accident event.

We are proposing a new evaluation of the source term for the radioactive nuclei release during a severe accident, evaluation that may lead to a better preparedness and more flexible planning from the authority and the utility owners that means better fund, material and human resources usage. Knowing that an under-evaluation of the radioactive release leads to inefficient mitigation actions under low resources allocated to the mitigation teams and an overevaluation leads sometimes to waste of resources by the mitigating teams, the proper evaluation means an economy for resources, both human and material.

The work has been partly funded by the Sectoral Operational Programme Human Resources Development 2007-2013 of the Ministry of European Funds through the Financial Agreement POSDRU/159/1.5/S/132395 and partly by the Sectoral Operational Programme Human Resources Development 2007-2013 of the Ministry of European Funds through the Financial Agreement POSDRU/159/1.5/S/134398.

\section{References}

1. G. Negut, Contributii la studiul dinamicii proceselor termohidraulice tranzitorii din reactoarele centralei nuclearoelectrice de la Cernavodă, $\mathrm{PhD}$ thesis, Universitatea Politehnica Bucuresti, Bucharest, 2006

2. O. Akalin, C. Blahnik, B. Phan, F. Rance, Fuel temperature escalation in severe accidents, in Canadian Nuclear Society 6th Annual CNS Conference Ottawa, Canada, June 3-4, 1985 (1985)

3. M. Mladin, D. Dupleac, I. Prisecaru, SCDAP/RELAP5 application to CANDU6 fuel channel analysis under postulated LLOCA/LOECC conditions, Nucl. Eng. Design 239, 353 (2008) 
4. M. Mladin, D. Dupleac, I. Prisecaru, Modifications in SCDAP code for early phase degradation in a CANDU fuel channel, Ann. Nucl. Energy 36, 634 (2009)

5. A. Budu, Contributii la studiul accidentelor din centralele nuclearoelectrice CANDU, PhD thesis, Universitatea Politehnica Bucuresti, Bucharest, 2011
6. Canadian Nuclear Safety Commission, Study of consequences of a hypothetical severe nuclear accident and effectiveness of mitigation measures - Draft report, June 2014, e-Doc 4160563 (WORD), e-Doc 4449079 (PDF), p. 25, http://www.opg.com/ about/safety/nuclear-safety/Documents/CNSC_Study.pdf

Cite this article as: Andrei Razvan Budu, Gabriel Lazaro Pavel, Beyond designed functional margins in CANDU type NPP. Radioactive nuclei assessment in an LOCA type accident, EPJ Nuclear Sci. Technol. 1, 10 (2015) 